\title{
Kinetic structure and wave properties associated with sharp dipolarization front observed by Cluster
}

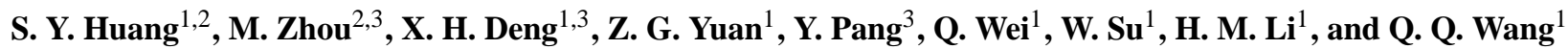 \\ ${ }^{1}$ School of Electronic Information, Wuhan University, Wuhan 430072, China \\ ${ }^{2}$ State Key Laboratory of Space Weather, Chinese Academy of Sciences, Beijing 100190, China \\ ${ }^{3}$ Institute of Space Science and Technology, Nanchang University, Nanchang 330031, China
}

Correspondence to: S. Y. Huang (shiyonghuang@msn.com)

Received: 17 March 2011 - Revised: 29 October 2011 - Accepted: 24 December 2011 - Published: 9 January 2012

\begin{abstract}
Multiple dipolarization fronts (DFs) were observed by Cluster spacecraft in the magnetotail during a substorm. These DFs were kinetic structures, embedded in the bursty plasma flow, and moved earthward (mainly) and dawnward. Intense electric field, parallel and perpendicular currents were detected in the DF layer. These front layers were energy dissipation region (load region) where the energy of electromagnetic fields were transferred to the plasma thermal and kinetic energy. This dissipation was dominated by electrons. There were enhancements of plasma waves around the DF region: wavelet results show that wave activities around the ion cyclotron frequency in the front layer were generated by Alfvén ion cyclotron instability; whistler waves were also detected before, during and after the DFs, which are triggered by electron temperature anisotropy and coincident with enhancement of energetic electron fluxes. The observation of these waves could be important for the understanding of evolution of DF and electron energization during the substorm. We discuss the generation mechanism of the DFs and suggest that these DFs were generated in the process of transient reconnection, and then traveled toward the Earth.
\end{abstract}

Keywords. Magnetospheric physics (Energetic particles, precipitating; Magnetotail; Plasma waves and instabilities)

\section{Introduction}

Substorm is considered as the most important dynamic process in the magnetosphere and ionosphere. A strong increase of magnetic field component $B_{\mathrm{Z}}$ normal to the neutral plane is known as the magnetic field dipolarization. Dipolarization in the near-Earth plasma sheets is a common signature associated with substorm expansion onset (Baker et al., 1978; Baumjohann et al., 1999, and references therein). Dipolarization phenomena are observed through a large range of magnetotail, from $-5 R_{\mathrm{E}}$ (the Earth's radius) to $-31 R_{\mathrm{E}}$ (Nakamura et al., 2002, 2005; Ohtani et al., 2004; Shiokawa et al., 2005). Dipolarization between $X=-8 R_{\mathrm{E}}$ and $X=$ $-12 R_{\mathrm{E}}$ is suggested to be either caused by the braking of fast plasma flow in the near-Earth tail region (Shiokawa et al., 1997), or the disruption of the cross-tail current (Lui, 1996).

Analyzing the database of Geotail, Ohtani et al. (2004) statistically studied the fast flow in the plasma sheet and found that the magnetic field became dipolar in the fast plasma flow and the sharp DF tends to be preceded by a transient decrease in $B_{\mathrm{Z}}$. They compared their observations with isothermal two-fluid simulations and suggested that the asymmetric $B_{\mathrm{Z}}$ bipolar structure of dipolarization front (DF) was due to the passage of a magnetic island which was generated by multiple $\mathrm{X}$ lines. On the other hand, full-particle simulations with open boundaries showed that the DF is a new regime of transient reconnection in contrast to flux pileup region and secondary islands or plasmoids generated by magnetic reconnection (Sitnov et al., 2009). They also found that the DF was a kinetic structure with thickness comparable with ion inertial length or larmor radius.

Recently, earthward propagating sharp DFs were observed in the magnetotail by THEMIS spacecraft (Runov et al., 2009; Zhou et al., 2009; Sergeev et al., 2009; Deng et al., 2010). The sharp DF was interpreted as vertical thin current sheet embedded within the earthward fast plasma flow (Sergeev et al., 2009). They suggested the DF was a complicated kinetic-scale structure that combines with a 
(a)
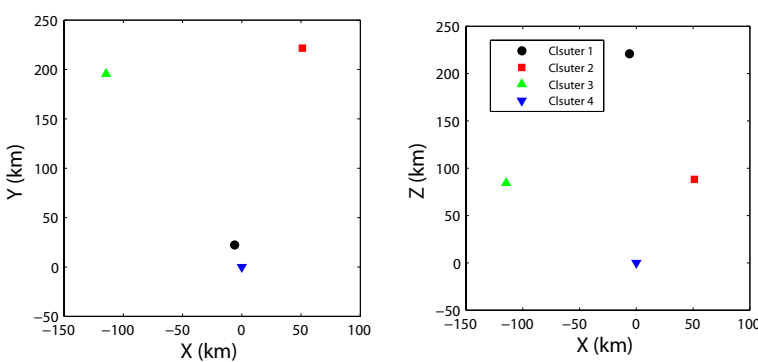

(b)
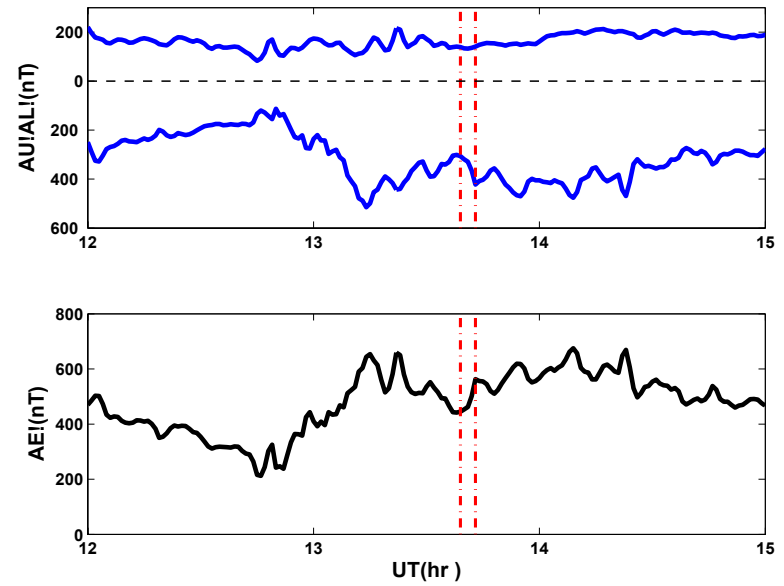

Fig. 1. (a) The relative positions of the four Cluster spacecraft at 13:39 UT on 29 August 2003 are presented in the GSM coordinate. Cluster-4 was located at $(-17.48,-1.77,2.87) R_{\mathrm{E}}$. (b) $\mathrm{AU}, \mathrm{AL}$ and AE index from 12:00 to 15:00 UT on 29 August 2003. The red dashed vertical lines mark the time interval of 13:37-13:47 UT.

number of small scale elements. Zhou et al. (2009) and Deng et al. (2010) found the energetic electron injection was closely related with DFs and burst bulk flows. They also suggested that DFs were located at the leading edge of plasma bubble (Zhou et al., 2009). The plasma bubble was proposed to explain the bursty bulk flow in the magnetotail. It is suggested as a plasma depleted flux tube, where plasma pressure reduces and magnetic pressure increases (maintaining approximately constant total pressure), associated with fast plasma flow (Chen and Wolf, 1993; Sergeev et al., 1996).

In addition, intense wave activities were associated with the DFs. Lower hybrid waves, electrostatic electron cyclotron harmonic waves, and nonlinear electrostatic structures such as electrostatic solitary waves and double layers were detected around the DF (Zhou et al., 2009; Deng et al., 2010).

We define the sharp DF as a sharp increase of $B_{\mathrm{Z}}$ with variation amplitude $\delta B_{\mathrm{z}}>10 \mathrm{nT}$ in less than $30 \mathrm{~s}$, and without large fluctuation of $B_{\mathrm{z}}$ preceding front crossing in the central plasma sheet where requires ion plasma $\beta>1$. In this paper, we utilize data from four Cluster spacecraft to investigate the kinetic structure and wave properties associated with sharp DF in detail. The advantage of Cluster over THEMIS for studying small scale structure is that the inter-distance be- tween four spacecraft is much smaller (around $200 \mathrm{~km}$ in the year of 2003). High resolution data from Cluster spacecraft are used for this analysis. The FGM instrument provides $22 \mathrm{~Hz}$ magnetic field data (Balogh et al., 1997), and the EFW instrument provides $25 \mathrm{~Hz}$ electric field data (Gustafson et al., 1997). Spin resolution (4s) ion plasma data is obtained from the CIS instrument (Rème et al., 2001). The electron distribution is from the PEACE instrument (Johnstone et al., 1997). High-energy electron and proton differential particle flux data are obtained from the RAPID instrument (Wilken et al., 2001). Electric and magnetic fields power-spectrograms are from the STAFF experiment (Cornilleau-Wehrlin et al., 2003).

The remainder of this paper is organized as follows. In Sect. 2, we present the observation of multiple DFs on $29 \mathrm{Au}-$ gust 2003. In Sect. 3, kinetic structure of the DFs is analyzed in detail. In Sect. 4, we show wave properties around the DFs. The results are discussed in Sect. 5 and we summarize our results in Sect. 6.

\section{Observation overview}

In this paper, we report Cluster observations of the multiple DFs during the interval of 13:37-13:47 UT on 29 August 2003. Figure 1a shows the relative position of the Cluster spacecraft at 13:39 UT in the Geocentric Solar Magnetospheric (GSM) coordinate. All the variables are presented in GSM coordinate system unless otherwise specified. Cluster4 was located around $(-17.48,-1.77,2.87) R_{\mathrm{E}}$ in the magnetotail, and four Cluster spacecraft formed a tetrahedron with a maximum inter-distance of about $250 \mathrm{~km}$. All four spacecraft were in the post-midnight sector.

Figure $1 \mathrm{~b}$ shows the $\mathrm{AU}, \mathrm{AL}$, and $\mathrm{AE}$ index between 12:00 UT and 15:00 UT. The red dashed vertical lines mark the interval of 13:37-13:47 UT when the DFs were observed. AE index started to increase at 12:42 UT and reached up to $700 \mathrm{nT}$ at 13:15 UT. During the time interval when multiple DFs were detected, the AL index decreased and the AE index increased up to $570 \mathrm{nT}$ after a slight drop. The indexes suggest that the DFs were detected during a substorm expansion phase.

Figure 2 shows an overview of the Cluster-4 observations from 13:37 UT to 13:47 UT. On the scale of Fig. 2, the observations of all four spacecraft are essentially identical. $B_{\mathrm{x}}$ was fluctuated around zero with very small amplitude, less than $10 \mathrm{nT}$, during the whole time interval (Fig. 2a), and the ion plasma $\beta$ (the ratio of the ion pressure to the magnetic pressure) was larger than 1 , which implies that spacecraft was located in the central plasma sheet. The magnetic field $B_{\mathrm{Z}}$ increased quickly from $1 \mathrm{nT}$ to $19 \mathrm{nT}$ at 13:39:34-13:39:38 UT and 13:43:27-13:43:32 UT preceded by a much less negative dip (Fig. 2a). It means that two DFs passed the Cluster spacecraft in the central plasma sheet. The speed of plasma flow is up to $300 \mathrm{~km} \mathrm{~s}^{-1}$ at the first DF and $500 \mathrm{~km} \mathrm{~s}^{-1}$ at the second 


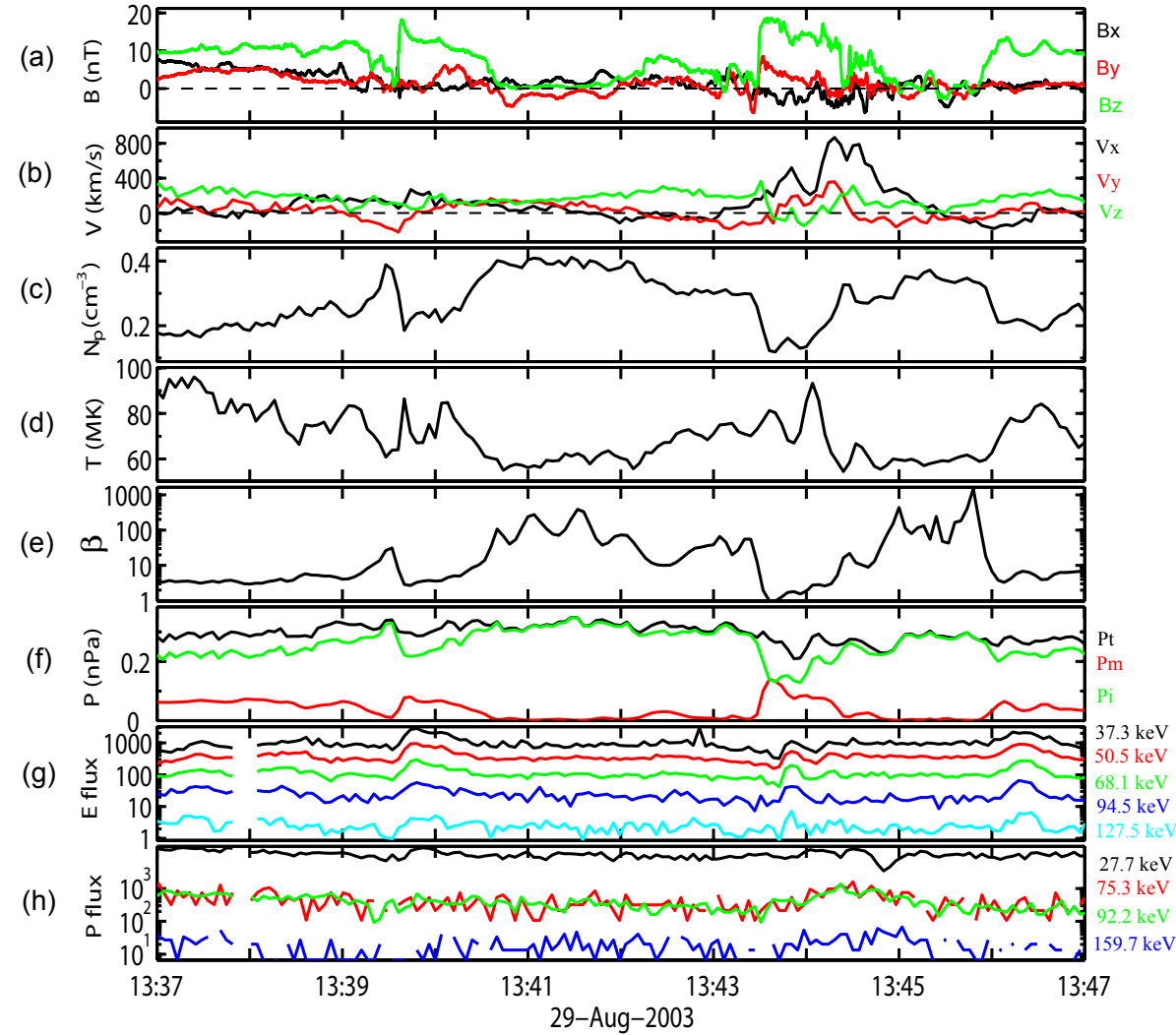

Fig. 2. Overview of magnetic field, ion plasma data, and electron plasma data observed by Cluster-4 between 13:37 UT to 13:47 UT on 29 August 2003. The top panel shows the three components of magnetic field. The next three panels show the three components of ion plasma velocity, ion plasma density and temperature, respectively. The fifth panel shows the ion plasma $\beta$ and the sixth panel shows the thermal pressure, magnetic pressure and total pressure. The last two panels show electron differential fluxes $\left(1 /\left(\mathrm{cm}^{2} \mathrm{str} \mathrm{s} \mathrm{keV}\right)\right)$ and proton differential fluxes $\left(1 /\left(\mathrm{cm}^{2}\right.\right.$ str s keV $\left.)\right)$ measured by the RAPID instrument.

DF. Both flows around DFs have large dawnward component. After the crossing of DFs, the Y component of plasma flow reveals from dawnward $\left(-V_{\mathrm{y}}\right)$ to duskward $\left(+V_{\mathrm{y}}\right)$ direction, which may be due to the passage of a vortex. The observations of two DFs were separated by less than $4 \mathrm{~min}$. The observed DFs have typical signatures similar as those sharp DFs observed by THEMIS, such as sharp $B_{\mathrm{Z}}$ increase, ion plasma density decrease (Fig. 2c), temperature increase (Fig. 2d), and $\beta$ decrease (Fig. 2e). Inside the DFs, magnetic pressure increased while thermal pressure decreased and the total pressure (Fig. 2f) did not vary a great deal, which is similar as the plasma bubble in the near earth region (Chen and Wolf, 1993; Sergeev et al., 1996). The energetic electron fluxes between $37.3 \mathrm{keV}$ and $127.5 \mathrm{keV}$ increased around the DFs. The fluxes started to increase when the Cluster encountered the first front, while there was a slight lag between the arrival of the second front and electron fluxes increase (Fig. 2g). High energy ion fluxes, between $27.7 \mathrm{keV}$ and $92.2 \mathrm{keV}$, also show some enhancements at both DFs (Fig. 2h). Such ion fluxes enhancements have been observed by previous researches (e.g. Ohtani et al., 1992). In this pa- per we do not discuss the detailed structures of $B_{\mathrm{Z}}$ increase at around 13:44:20 UT and 13:45:50 UT since they don't satisfy our criteria of selecting sharp DF.

\section{Kinetic structure of DF}

To determine the velocity of these fronts, multi-spacecraft timing analysis was used. The timing analysis results are summarized in Table 1. It is found that both fronts moved earthward, which is consistent with recent THEMIS observations (Runov et al., 2009; Zhou et al., 2009). However, the fronts also moved in the dawnward direction since the normal direction deviated in the Y-direction. The normal velocities of two fronts, i.e. $223 \mathrm{~km} \mathrm{~s}^{-1}$ and $207 \mathrm{~km} \mathrm{~s}^{-1}$, are close to the ion plasma velocities in the normal direction with $195 \mathrm{~km} \mathrm{~s}^{-1}$ and $236 \mathrm{~km} \mathrm{~s}^{-1}$, respectively. It implies that the DFs moved together with the fast plasma flow, which is consistent with the previous observations (Runov et al., 2009; Zhou et al., 2009). The thickness of the DF could be estimated by $V_{\mathrm{n}} \cdot t$, where $V_{\mathrm{n}}$ is the normal speed of the front and $t$ is the duration of the DF passed the spacecraft. We choose 
Table 1. Timing analysis results.

\begin{tabular}{ccccc}
\hline Event & Time (UT) & Normal direction & Normal velocity & Thickness of DF \\
\hline DF1 & $13: 39: 30-13: 39: 40$ & $0.55,-0.82,0.14$ & $223 \mathrm{~km} \mathrm{~s}^{-1}$ & $1000 \pm 112 \mathrm{~km}$ \\
DF2 & $13: 43: 20-13: 43: 40$ & $0.76,-0.57,0.32$ & $207 \mathrm{~km} \mathrm{~s}^{-1}$ & $1035 \pm 145 \mathrm{~km}$ \\
\hline
\end{tabular}

(a)

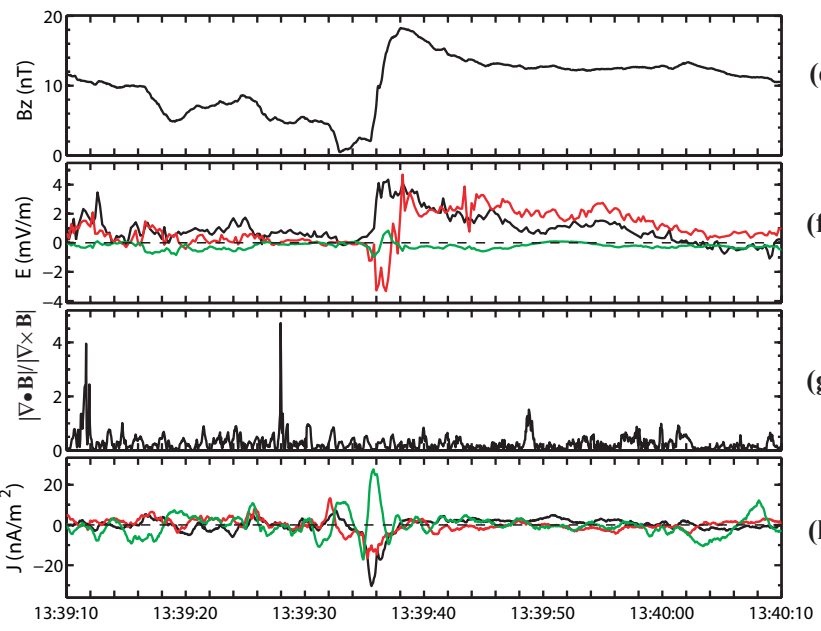

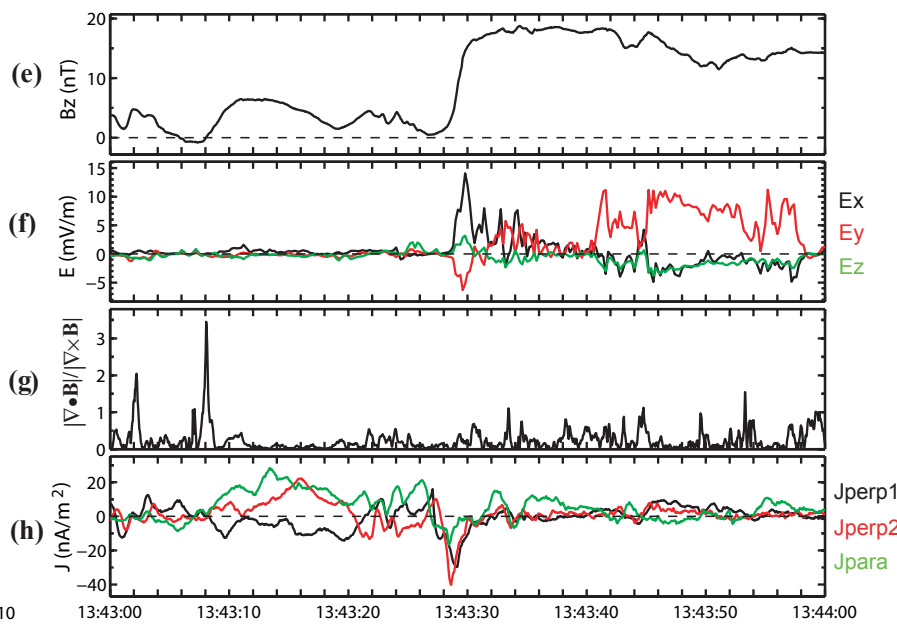

Fig. 3. Overview of electric field and electric current density around two DFs. (a)-(b) and (e)-(f) are the magnetic field component $B_{\mathrm{Z}}$ and electric field of Cluster-4, respectively. (c) and (g) are the values of $|\nabla \cdot \boldsymbol{B}| /|\nabla \times \boldsymbol{B}|$. (d) and (h) are electric current density in the field aligned coordinate (FAC).

the $t$ based on the profile from the minimum of $B_{\mathrm{z}}$ to the maximum of $B_{\mathrm{z}}$. The thickness of the first front is estimated to be about $1000 \pm 112 \mathrm{~km} \sim \rho_{i}\left(\rho_{i} \sim 964 \mathrm{~km}\right.$, is the local ion gyro-radius). The thickness of the second front is estimated to be about $1035 \pm 145 \mathrm{~km} \sim 0.85 \rho_{i}\left(\rho_{i} \sim 1217 \mathrm{~km}\right)$. The thickness of kinetic-scale DF is consistent with results of obtained by THEMIS (Runov et al., 2009; Sergeev et al., 2009).

Figure 3 presents electric field and electric current density during the passage of two DFs. Two components of electric field are measured in the spin plane of the spacecraft which is nearly parallel to the geocentric solar ecliptic (GSE) X-Y plane, the third component can be obtained by the assumption of $\boldsymbol{E} \cdot \boldsymbol{B}=0$ (Borg et al., 2005). This assumption is expected to be valid everywhere except in the electron diffusion region where the electrons are not frozen in the magnetic field lines. Before the arrival of DFs, electric fields were very small, less than $4 \mathrm{mV} \mathrm{m}^{-1}$ (Fig. $3 \mathrm{~b}$ and $\mathrm{f}$ ). There were intense electric fields in the first front and the electric fields went up to $15 \mathrm{mV} \mathrm{m}^{-1}$ in the second one.

The electric current density is calculated by the Curlometer method (Dunlop et al., 2002). Figure 3c and $g$ are the values of $|\nabla \cdot \boldsymbol{B}| /|\nabla \times \boldsymbol{B}|$. Figure $3 \mathrm{~d}$ and h displays electric current density in Field Align coordinate (FAC). The $|\nabla \cdot \boldsymbol{B}| /|\nabla \times \boldsymbol{B}|$ reveals the computational efficiency of Curlometer method. The smaller values of $|\nabla \cdot \boldsymbol{B}| /|\nabla \times \boldsymbol{B}|$, the more reliable the electric current density was. The values of $|\nabla \cdot \boldsymbol{B}| /|\nabla \times \boldsymbol{B}|$ are small (Fig. 3c and g), i.e. less than 0.5 in the front, which indicates the estimated current density are reliable. There are strong parallel and perpendicular components of current density at the DFs while current is small before and after the fronts (Fig. 3d and h). It means that the DFs not only correspond to strong transverse current, but also field aligned current. This field-aligned current may have close correlation with auroral activities.

Figure 4 shows $\boldsymbol{J} \cdot \boldsymbol{E}$ term associated with two DFs. Electron current density is estimated by $\boldsymbol{J}_{\mathrm{e}}=\boldsymbol{J}_{\text {tot }}-\boldsymbol{J}_{\mathrm{i}}$, where $\boldsymbol{J}_{\text {tot }}$ is the total current density, $\boldsymbol{J}_{\mathrm{i}}=N_{\mathrm{i}} e \boldsymbol{V}_{\mathrm{i}}$ is the proton current density, $N_{\mathrm{i}}$ is the proton density, $e$ is the magnitude of the electron charge and $\boldsymbol{V}_{\mathrm{i}}$ is the velocity of proton plasma flow. Our event was not observed during a storm-time, so the heavy ion species, such as $\mathrm{O}^{+}, \mathrm{He}^{+}$and $\mathrm{He}^{++}$, are tenuous. In addition, there were no large energetic ion fluxes (with energy higher than $40 \mathrm{keV}$ ) increase, so $\boldsymbol{V}_{\mathrm{i}}$ contributed by high energy ions can be ignored. Therefore, the estimated $\boldsymbol{J}_{\mathrm{i}}$ should be reliable for the following analysis. The positive values of $\boldsymbol{J} \cdot \boldsymbol{E}$ indicate that the energy of electromagnetic field is transferred to plasma thermal and kinetic energy, i.e. a load region, while the negative $\boldsymbol{J} \cdot \boldsymbol{E}$ implies that particles are losing energy to electromagnetic field, i.e. a generator region. The positive values of total energy dissipation imply the fronts are load region at the front, which is consistent 

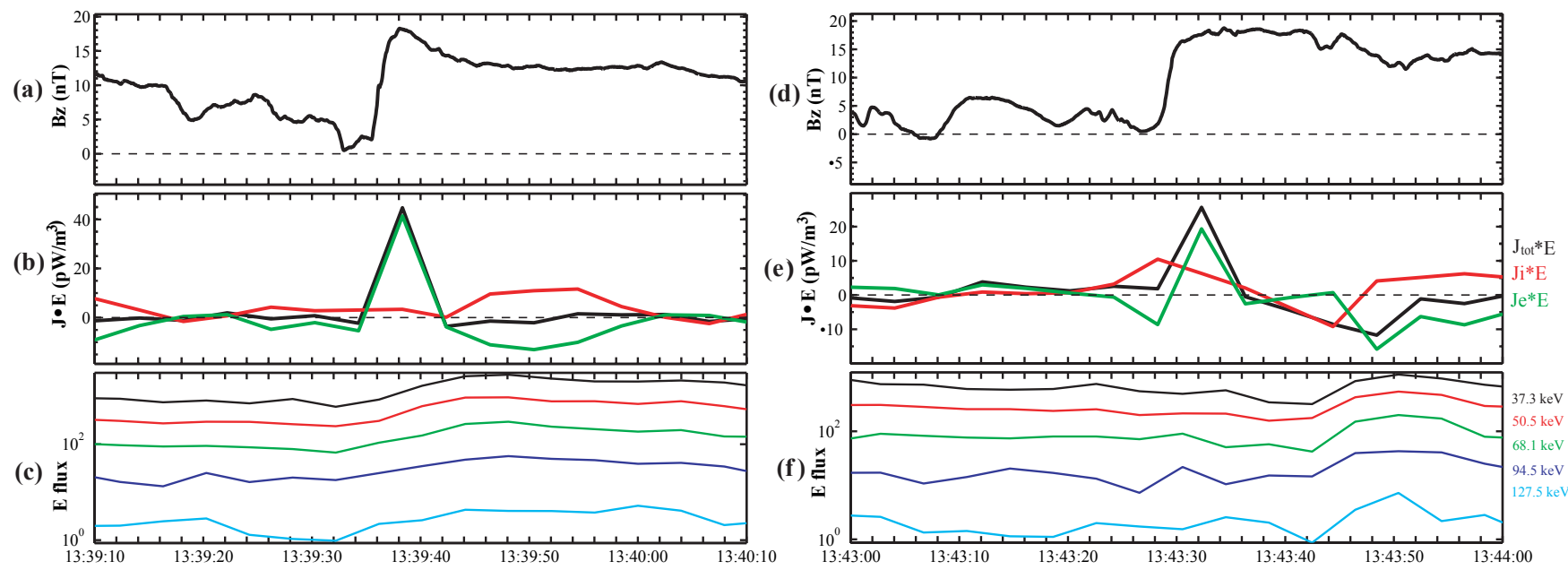

Fig. 4. Magnetic filed $B_{\mathrm{Z}}, \boldsymbol{J} \cdot \boldsymbol{E}\left(\boldsymbol{J}_{\mathrm{tot}} \cdot \boldsymbol{E}, \boldsymbol{J}_{\mathrm{i}} \cdot \boldsymbol{E}\right.$, and $\left.\boldsymbol{J}_{\mathrm{e}} \cdot \boldsymbol{E}\right)$, and the differential fluxes of energetic electrons $\left(1 /\left(\mathrm{cm}^{2} \mathrm{str} \mathrm{skeV}\right)\right)$ are displayed from top to bottom panels.

with the simulation (Sitnov et al., 2009). The energy dissipation in fronts is dominated by electrons since $\boldsymbol{J}_{\mathrm{e}} \cdot \boldsymbol{E}>\boldsymbol{J}_{\mathrm{i}} \cdot \boldsymbol{E}$. The electron fluxes started to increase when the electromagnetic field energy was dissipated by electrons in the first front (Fig. $4 \mathrm{~b}$ and c). However, the electron fluxes increased a few seconds later than the $\boldsymbol{J}_{\mathrm{e}} \cdot \boldsymbol{E}$ became positive at the second front (Fig. 4e and f).

\section{Wave analysis}

In this section, we investigate the wave properties associated with the DFs. First, we investigate the waves below the lower hybrid frequency. Figure 5 shows the frequencytime spectrogram of three components of magnetic field measured by Cluster-4. Ion cyclotron frequency and lower hybrid frequency are marked by blue and white traces in each frequency-time spectrogram. Wave activities around the ion cyclotron frequency were observed in the front layer. The most remarkable feature is the inverse cascade in the power spectrum of $B_{\mathrm{Z}}$ before the arrival of DFs (13:39:0013:39:34 UT and 13:43:05-13:43:27 UT). The inverse cascade was mainly between $0.02-0.1 \mathrm{~Hz}$ for the first $\mathrm{DF}$ and $0.01-0.09 \mathrm{~Hz}$ for the second DF (Fig. 5b). There were similar features in the $B_{\mathrm{y}}$ component (Fig. $5 \mathrm{~d}$ ) and $B_{\mathrm{x}}$ component (Fig. 5f). Figure $5 \mathrm{~g}$ and $\mathrm{h}$ also shows the power spectral density (PSD) during both DFs. We can see that the PSDs enhance around the ion cyclotron frequency.

Second, there were higher frequency wave activities associated with the DFs. The waves in the frequency range from $10 \mathrm{~Hz}$ to $4000 \mathrm{~Hz}$ observed by STAFF instrument are analyzed by the Propagation Analysis of STAFF-SA Data with Coherency Tests (PRASSADCO) tool (Santolik et al., 2003). Figure 6 presents the polarization analysis results between 13:37 UT and 13:47 UT. Black curve on all panels corresponds to the electron cyclotron frequency. Figure $6 \mathrm{a}$ and $b$ shows the power spectral density of magnetic field and electric field, respectively. Figure $6 \mathrm{c}$ shows the planarity of polarization, and Fig. $6 \mathrm{~d}$ shows the sense of polarization, in which the values of $C_{B}>0$ indicate a right-hand polarized wave and the values of $C_{B}<0$ imply a left-hand polarized wave. Figure 6e shows the propagation angles of the waves with respect to the ambient magnetic field. These angles are obtained by the Singular Value Decomposition (SVD) method (Santolík et al., 2003). We found that there were several intermittent electromagnetic wave emissions shown in the power spectrogram of magnetic field and electric field (Fig. 6a and b). The frequency range of waves is between lower hybrid frequency and electron cyclotron frequency. Around the first front (13:39:30-13:39:53 UT), the power spectral densities of both magnetic fields and electric fields enhanced (red color), which is an evidence of electromagnetic wave emission. The frequency of this wave is from $\sim 60 \mathrm{~Hz}$ to $\sim 200 \mathrm{~Hz}$, i.e. around $100 \mathrm{~Hz}$. The polarization senses of this intermittent wave are positive, about 1 (see Fig. 6d). The propagation angles of the wave are less than $20^{\circ}$ (Fig. 6e). The polarization planarity of this wave are near 1 (Fig. 6c), which indicates that this wave satisfy the plane wave assumption very well. Therefore, this intermittent wave is right-hand polarized and quasi-parallel propagated, consistent with whistler wave. Similar whistler waves were observed around 13:37:27-13:37:50 UT, 13:43:09-13:43:15 UT, 13:43:40-13:43:57 UT, 13:44:1013:44:25 UT, and 13:45:57-13:46:11 UT, respectively. In summary, the whistler waves were detected before, during and after the DFs. 
(a)

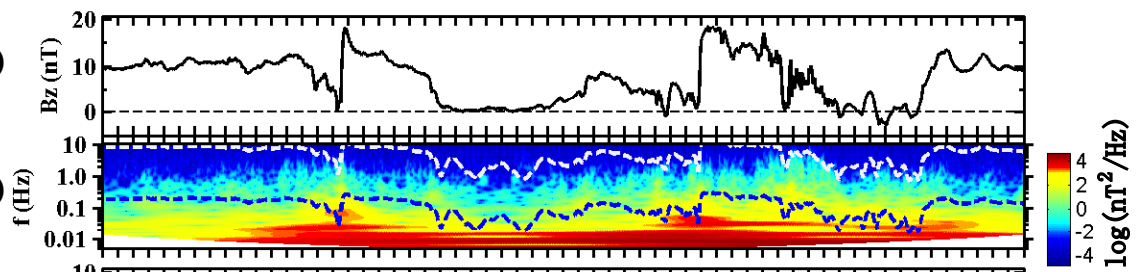

(c)

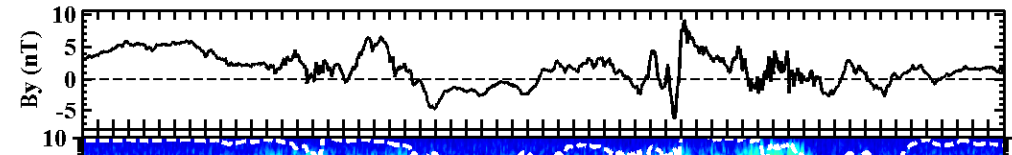

(d)

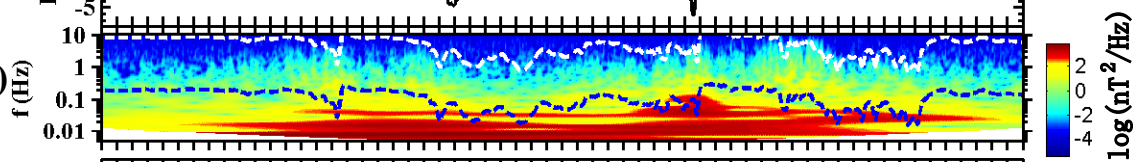

(e)

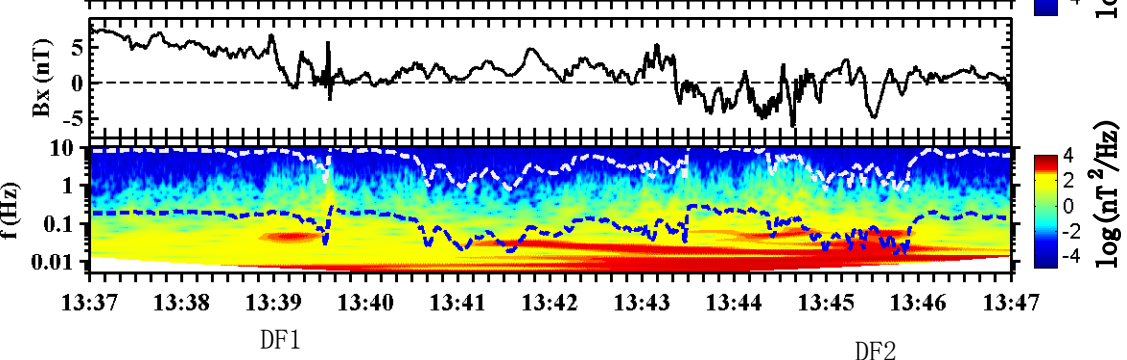

\section{(f)}

$\mathrm{DF} 1$

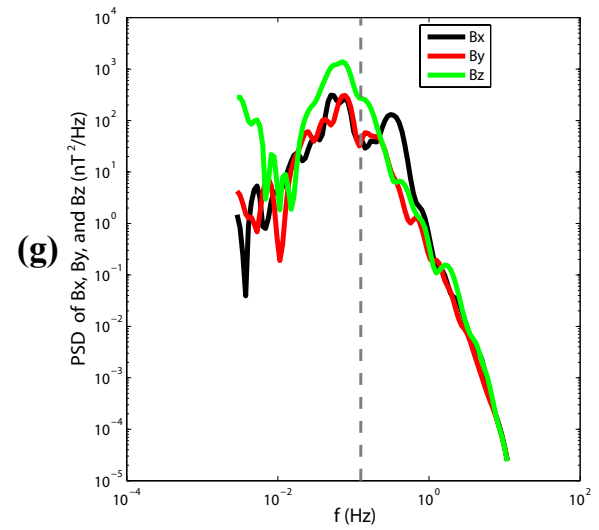

(h)

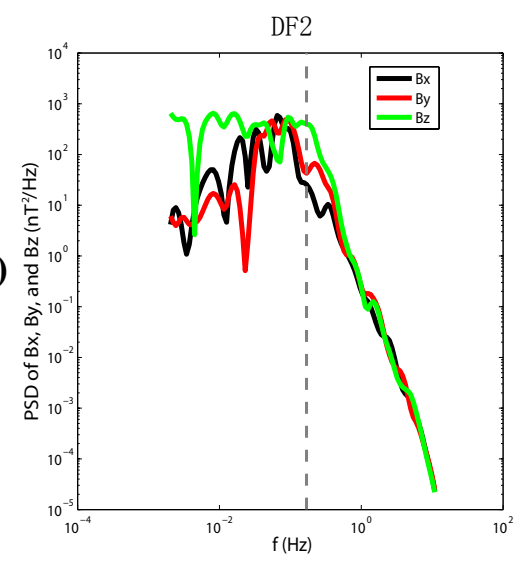

Fig. 5. Power spectrograms of magnetic fields recorded by Cluster-4. (a), (c), and (e) are three components of magnetic field $B_{\mathrm{Z}}, B_{\mathrm{y}}$ and $B_{\mathrm{X}}$, respectively. (b), (d), and (f) are power spectrogram of three components of magnetic field $B_{\mathrm{Z}}, B_{\mathrm{y}}$ and $B_{\mathrm{X}}$ obtained via wavelet analysis. The blue and white traces show the Ion cyclotron frequency and lower hybrid frequency in each frequency-time spectrogram. (g) and (h) are the power spectrum densities (PSDs) around two DFs. The vertical dashed gray lines show the ion cyclotron frequency.

\section{Discussion}

Sitnov et al. (2009) found that the fronts are kinetic scale structure and the energy dissipation is dominated by ions in the front layer via two-dimensional full particle simulation. Figure $4 \mathrm{~b}$ and $4 \mathrm{e}$ shows the DF is a load region $\left(\boldsymbol{J}_{\text {tot }} \cdot \boldsymbol{E}>0\right)$ where the energy of electromagnetic field transfers to the plasma and kinetic energy, and the energy dissipation in fronts is dominated by electrons $\left(\boldsymbol{J}_{\mathrm{e}} \cdot \boldsymbol{E}>\boldsymbol{J}_{\mathrm{i}} \cdot \boldsymbol{E}\right)$, instead of ions. At the first front, the energetic electrons enhancement was companied with positive values of $\boldsymbol{J}_{\mathrm{e}} \cdot \boldsymbol{E}$ (Fig. 4c). However, there was a slight lag between the positive $\boldsymbol{J}_{\mathrm{e}} \cdot \boldsymbol{E}$ and electron fluxes increase at the second front (Fig. 4f).

DFs were found associated with fruiful wave activities from below the lower hybrid frequency to above the electron cyclotron frequency (Deng et al., 2010; Zhou et al., 2009). Here, we found that there were wave activities around the ion cyclotron frequency. Lui et al. (2008) detected waves with inverse cascade feature around dipolarization by THEMIS spacecraft. They suggested that the waves below ion cyclotron frequency may originate from the drift-driven electromagnetic ion cyclotron instability or an ordinary mode instability similarly driven by the cross-field ion drift. The electromagnetic ion cyclotron instability propagates along the magnetic field, while the Alfvén ion cyclotron instability characterized by the ordinary mode propagates in quasiperpendicular direction with respect to local magnetic field (Yoon et al., 2009). We utilized the $k$-filtering technique to calculate the propagation angle of low frequency wave 
CLUSTER STAFF-SA 2003-08-29 13:36:59.162 - 2003-08-29 13:47:02.997

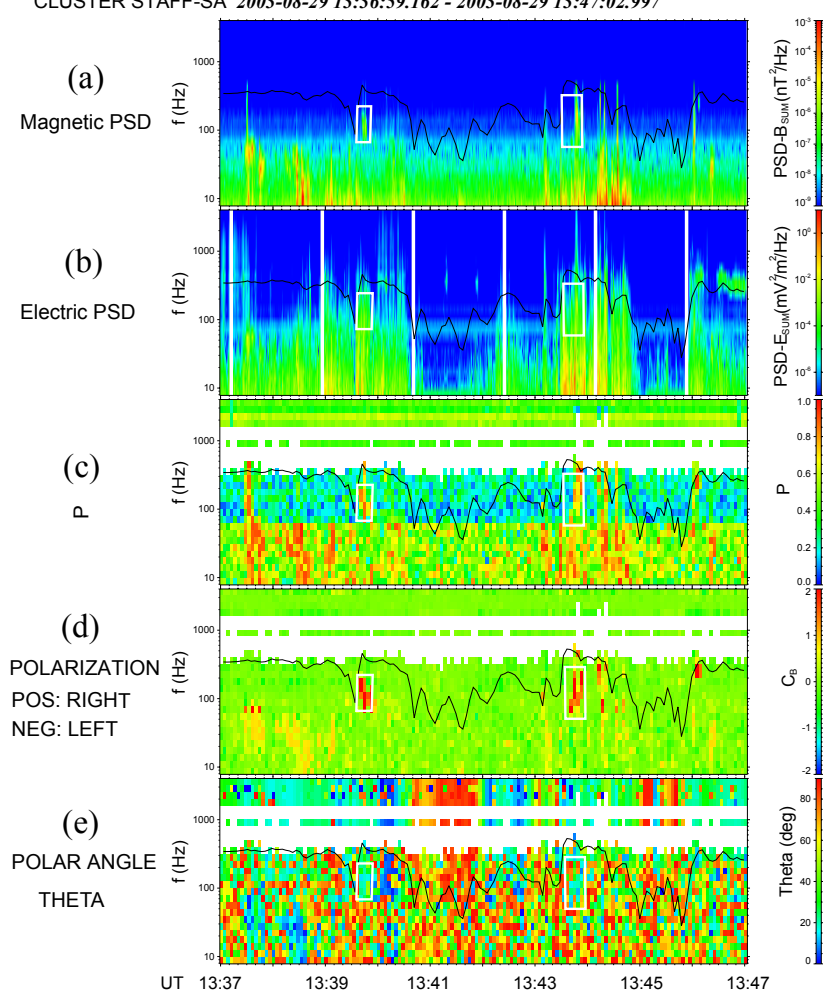

Fig. 6. Polarization analysis of waves from 8 to $4000 \mathrm{~Hz}$ between 13:37 UT and 13:47 UT on Cluster-4. Note that the frequency scale is logarithmic on all panels. From top to bottom are: (a) power spectral density of magnetic fields; (b) power spectral density of electric fields; (c) planarity of polarization; (d) the sense of polarization and (e) the propagation angles of the waves with respect to ambient magnetic field. Black curve on all panels corresponds to the electron cyclotron frequency. The white rectangles show the whistler wave emissions around two DFs.

activities. This technique allows one to estimate the magnetic wave field energy distribution in the frequency and wave vector domain from data measured simultaneously in several different points in space, under the assumption of (sufficient) stationarity of the time series (more details on this technique can be found in Pinçon and Lefeuvre, 1991; Pinçon and Motschmann, 1998; Sahraoui et al., 2003, 2010a). Therefore we could obtain wave vectors for a series of frequencies and propagation angles. This method was successfully used in the solar wind (Sahraoui et al., 2010b), magnetosheath (Sahraoui et al., 2003, 2006), and magnetotail (Huang et al., 2010). Regular configuration of Cluster spacecraft in this event satisfies the restriction of using this method. We found that the propagation angles mainly varied between $60^{\circ}$ and $120^{\circ}$ (not shown), i.e. quasi-perpendicular the ambient magnetic field. Therefore, the low frequency waves are probably the nearly quasi-perpendicular propagating waves excited by Alfvén ion cyclotron instability. In addition, the time duration of DFs, i.e. $\sim 10-20 \mathrm{~s}$ (corresponds $0.05-0.1 \mathrm{~Hz}$ ) is close to the frequencies of wave activities. Thus, the waves may play some roles in the time evolution of the DFs. The ion fluxes enhancements around DFs may be caused by the low wave activities with a frequency comparable to the local ion cyclotron frequency (Artemyev et al., 2009; Nosé et al., 2010; Ono et al., 2009).

We also observed quasi-parallel whistler waves before, during and after the DFs. Le Contel et al. (2009) explored quasi-parallel whistler waves before, during and after the dipolarization. In hot plasma the electron temperature anisotropy $T_{\perp \mathrm{e}} / T_{\| \mathrm{e}}>1$ is the source of whistler anisotropy instability (Gary and Wang, 1996, and references therein). Figure 7 shows the magnetic field $B_{\mathrm{z}}$, electron temperature anisotropy, power spectral density of whistler wave, and energetic electron fluxes between 13:37 UT and 13:47 UT recorded by Cluster-4. We found that there are good one to one correlations between whistler wave enhancements, electron anisotropies $\left(T_{\perp \mathrm{e}} / T_{\| \mathrm{e}}>1\right)$ and energetic electron fluxes increase. Gary and Wang (1996) have shown that fast wave-particle scattering could enhance whistler fluctuations for large electron anisotropies. In order to compare the observations with the theory of the whistler mode instability, we solved the dispersion relation under linear wave assumptions using the WHAMP code (Rǒnnmark, 1982). We choose $B_{0}=10 \mathrm{nT}$ as an average value of the background magnetic field. Other average plasma parameters are as follows: the plasma density was about $0.3 \mathrm{~cm}^{-3}$, proton temperature $T_{\mathrm{i}} \sim 7 \mathrm{keV}$, electron temperature $T_{\mathrm{e}} \sim 1.6 \mathrm{keV}$, electron anisotropy $\alpha_{\mathrm{e}} \sim 1.4$, ion isotropy $\alpha_{\mathrm{i}} \sim 1$. Figure 8 shows the results from WHAMP with above parameters as input. We obtain the maximum growth rate $\gamma_{\mathrm{m}} \approx 0.0332 \omega_{\mathrm{ce}}$ at the real frequency $\omega_{\mathrm{r}} \approx 0.217 \omega_{\mathrm{ce}}$. The bandwidth with $\gamma_{\mathrm{m}} \geq 0$ ranges from 0.078 to $0.289 \omega_{\text {ce }}$, which is from 22 to $81 \mathrm{~Hz}$ with electron cyclotron frequency $f_{\text {ce }}=280 \mathrm{~Hz}$ (ordinary frequency), consistent with the observed bandwidth shown in Fig. 6. Thus the results imply the whistler waves detected by the Cluster spacecraft were likely triggered by the electron temperature anisotropy. This is different from the tailward propagating negative DF, where the whistler waves were triggered by strong electron beams (Zhou et al., 2011). The generation mechanism of whistler waves around DF in different regions requires further detail analysis.

One interesting feature associated with the DFs was the increase of energetic electrons fluxes, which correlated well with the electron temperature anisotropy and whistler waves. In Fig. 7, major energetic electron fluxes enhancements were observed at the DF layer, which were also associated with large electric field and strong wave activities, such as low frequency wave activities and whistler waves. It has been shown that adiabatic betatron acceleration and Fermi acceleration are the mechanisms that energize electrons during dipolarization (Li et al., 1998; Ashour-Abdalla et al., 2011; Fu et al., 2011). However, there are some studies showing that adiabatic heating alone cannot account for the observed energy gain during substorm (Wu et al., 2006) and plasma waves 
(a)

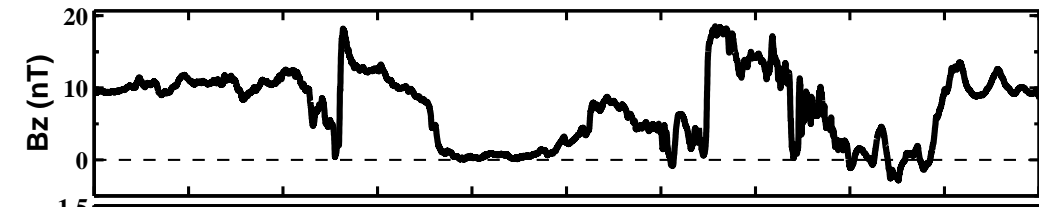

(b)

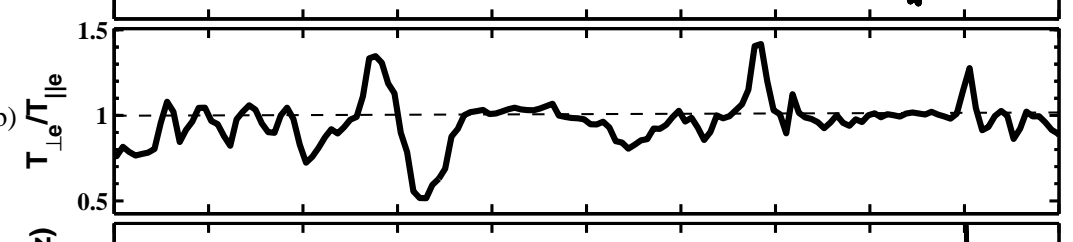

(c)

(d)

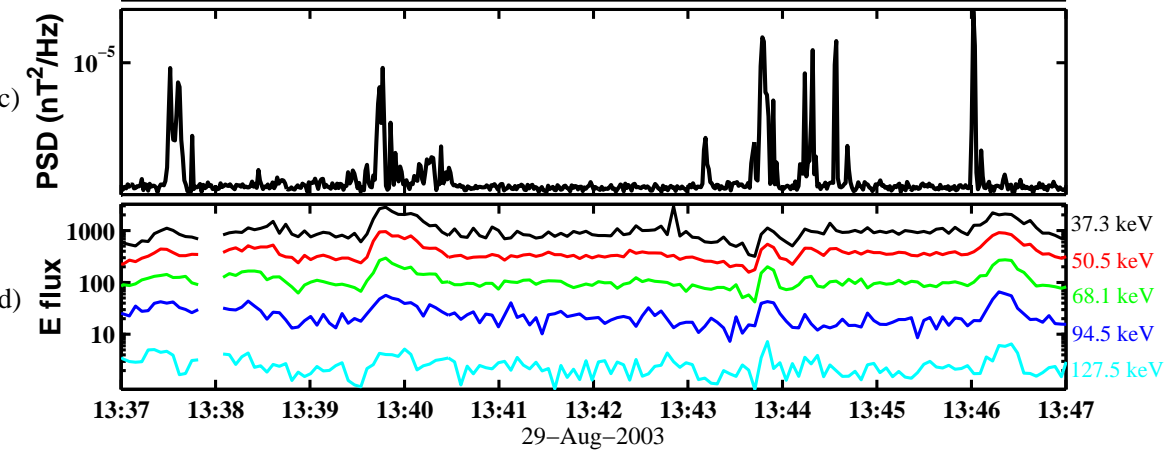

Fig. 7. (a) The Z-component of magnetic field; (b) ratios between the perpendicular and parallel electron temperatures, i.e. electron anisotropy; (c) total power spectrum density of magnetic field from $50 \mathrm{~Hz}$ to $250 \mathrm{~Hz}$, i.e. power spectrum density of whistler waves; (d) the differential fluxes of energetic electrons $\left(1 /\left(\mathrm{cm}^{2} \mathrm{str} \mathrm{s} \mathrm{keV}\right)\right)$.

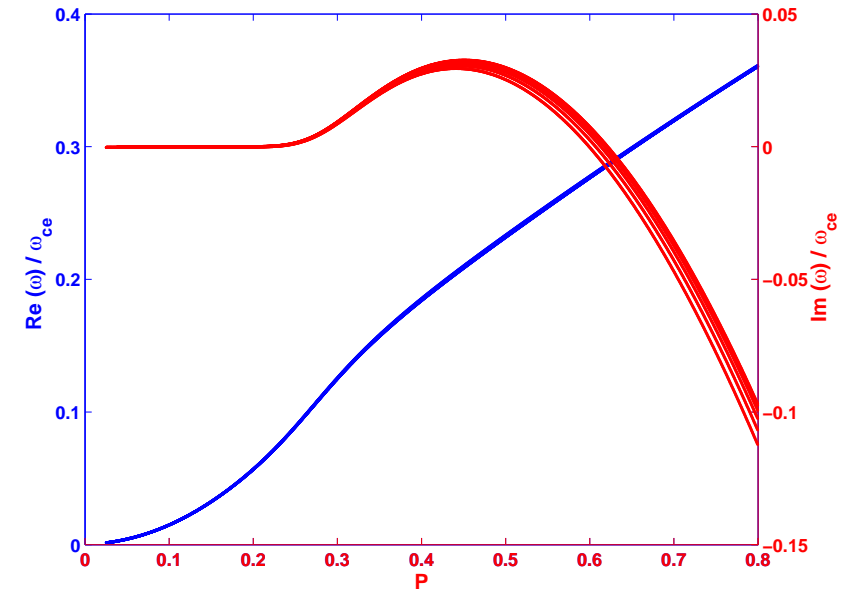

Fig. 8. WHAMP results: Real frequency $\operatorname{Re}(\omega) / \omega_{\text {ce }}$ (bule line) and Imaginary frequency, i.e. damping/growth rates, $\operatorname{Im}(\omega) / \omega_{\text {ce }}$ (red line) of the whistler anisotropy instability as function of the modulus of the wave number $P=k \rho_{\mathrm{e}}$ and for different wave angles (wave vectors with the respect of the ambient magnetic field) between $0^{\circ}$ and $5^{\circ}$ from top to bottom.

might play some roles in electron energization at the fronts (Zhou et al., 2009). Whistler waves observed here might be able to efficiently accelerate electrons. Electron anisotropy was probably caused by betatron acceleration as electrons moved from low magnitude ambient field to strong dipolarization region. Then, the electron anisotropy triggered the whistler waves. These whistler waves may further accelerate electrons to become energetic. Further investigation on the role of whistler wave to electronic dynamic requires selfconsistent kinetic simulation.

There are a number of simulations and observations to study the generation mechanism of DF. Ohtani et al. (2004) compared observations with two-fluid simulation, and suggested the asymmetric $B_{\mathrm{Z}}$ bipolar structure of DF was due to the passage of a magnetic island. Recently, Sitnov et al. (2009) found that the DF is a new regime of transient reconnection. It is well known that near earth neutral lines are often located at $X \sim-20 R_{\mathrm{E}}$. In this paper, we observed two DFs with bursty plasma flow at $X \sim-17.5 R_{\mathrm{E}}$, and found that the time interval was about 4 min between two fronts. Many features of the DFs observed here are similar to the simulations of Sitnov et al. (2009). Thus, we suggest that the DFs may be a result of interaction between ambient magnetic field and burst plasma flow from transient magnetic reconnection, then the DFs move earthward (mainly) and dawnward. The low frequency wave activities, i.e. around ion cyclotron frequency wave activities, may be also responsible for the time evolution of the DFs.

\section{Summary}

In summary, we present the observations of multiple DFs in the magnetotail on 29 August 2003 by the Cluster spacecraft. The fronts moved earthward (mainly) and dawnward, 
embedded in fast plasma flow. Plasma density and thermal pressure decreased, while magnetic pressure increased associated with the DFs, like bubble structures. The front layer was a thin current sheet with intense parallel and perpendicular current. There were energetic electron fluxes increase associated with the DFs. The thicknesses of the DFs were on the order of ion gyroradius length, which implies they were kinetic scale structures. We estimated the values of $\boldsymbol{J} \cdot \boldsymbol{E}$ and found the fronts were energy dispersion region which is dominated by electrons. Strong wave activities were detected around the front region. It is shown that there were intense wave activities around the ion cyclotron frequency in the front. These waves are likely generated by Alfvén ion cyclotron instability. Whistler waves were also detected before, during and after the DFs, which coincident well with electron temperature anisotropy and energetic electron fluxes enhancement. The results from WHAMP imply that these whistler waves are excited due to electron temperature anisotropy. We also discussed the generation mechanism of DF and the relationship among the fronts, the waves and electron dynamics. Further understanding the microphysics of DF requires multi-spacecraft observations and more sophisticated simulations, especially 3-D full particle simulation and large scale kinetic simulation.

Acknowledgements. This work is supported by the National Natural Science Foundation of China (NSFC) under grants 40890163, 41004060, and the Specialized Research Fund for State Key Laboratories. S. Y. Huang is also supported by the Fundamental Research Funds for the Central Universities. AE data were provided by the World Data Center for Geomagnetism in Kyoto. We thank the Cluster teams (FGM, CIS, EFW, PEACE, RAPID, and STAFF) and Cluster Active Archive for the high-quality data and successful operation.

Topical Editor I. A. Daglis thanks S. Machida and another anonymous referee for their help in evaluating this paper.

\section{References}

Artemyev, A. V., Zelenyi, L. M., Malova, H. V., Zimbardo, G., and Delcourt, D.: Acceleration and transport of ions in turbulent current sheets: formation of non-maxwelian energy distribution, Nonlin. Processes Geophys., 16, 631-639, doi:10.5194/npg-16631-2009, 2009.

Ashour-Abdalla, M., El-Alaoui, M., Goldstein, M., Zhou, M., Schriver, D., Richard, R., Walker, R., Kivelson, M. G., and Hwang, K.: Observations and Simulations of Nonlocal Acceleration of Electrons in Magnetotail Magnetic Reconnection Events, Nat. Phys., 7, 360-365, doi:10.1038/nphys1903, 2011.

Baker, D. N., Higbie, P. R., Hones, E. W., and Belian, R. D.: High resolution energetic particle measurements at 6.6RE 3. Low energy electron anisotropies and short-term substorm predictions, J. Geophys. Res., 83, 4863-4868, 1978.

Balogh, A., Dunlop, M. W., Cowley, S. W. H., Southwood, D. J. Thomlinson, J. G., Glassmeier, K. H., Musmann, G., Lühr, H., Buchert, S., Acuña, M. H., Fairfield, D. H., Slavin, J. A., Riedler,
W., Schwingenschuh, K., and Kivelson, M. G.: The Cluster Magnetic field Investigation, Sp. Sci. Rev., 79, 65-91, 1997.

Baumjohann, W., Hesse, M., Kokubun, S., Mukai, T., Nagai, T., and Petrukovich, A. A.: Substorm dipolarization and recovery, J. Geophys. Res., 104, 24995-25000, 1999.

Borg, A. L., Øieroset, M., Phan, T. D., Mozer, F. S., Pedersen, A., Mouikis, C., McFadden, J. P., Twitty, C., Balogh, A., and Reme, H.: Cluster encounter of a magnetic reconnection diffusion region in the near-Earth magnetotail on September 19, 2003, Geophys. Res. Lett., 32, L19105, doi:10.1029/2005GL023794, 2005.

Chen, C. X. and Wolf, R. A.: Interpretation of High-Speed Flows in the Plasma Sheet, J. Geophys. Res., 98, 21409-21419, doi:10.1029/93JA02080, 1993.

Cornilleau-Wehrlin, N., Chanteur, G., Perraut, S., Rezeau, L., Robert, P., Roux, A., de Villedary, C., Canu, P., Maksimovic, M., de Conchy, Y., Hubert, D., Lacombe, C., Lefeuvre, F., Parrot, M., Pinçon, J. L., Décréau, P. M. E., Harvey, C. C., Louarn, Ph., Santolik, O., Alleyne, H. St. C., Roth, M., Chust, T., Le Contel, O., and STAFF team: First results obtained by the Cluster STAFF experiment, Ann. Geophys., 21, 437-456, doi:10.5194/angeo21-437-2003, 2003

Deng, X., Ashour-Abdalla, M., Zhou, M., Walker, R., El-Alaoui, M., Angelopoulos, V., Ergun, R. E., and Schriver, D.: Wave and Particle Characteristics of Earthward Electron Injections Associated with Dipolarization Fronts, J. Geophys. Res., 115, A09225, doi:10.1029/2009JA015107, 2010.

Dunlop, M., Balogh, A., Glassmeier, K.-H., and Robert, P.: Four-point Cluster application of magnetic field analysis tools: The Curlometer. J. Geophys. Res., 107, 1384, doi:10.1029/2001JA005088, 2002.

Fu, H. S., Khotyaintsev, Y. V., André, M., and Vaivads, A.: Fermi and betatron acceleration of suprathermal electrons behind dipolarization fronts, Geophys. Res. Lett., 38, L16104, doi:10.1029/2011GL048528, 2011.

Gary, S. P. and Wang, J.: Whistler instability: Electron anisotropy upper bound, J. Geophys. Res., 101, 10749-10754, 1996.

Gustafson, G., Boström, R., Holback, B., Holmgren, G., Lundgren, A., Stasiewicz, K., Ahlen, L., Mozer, F. S., Pankow, D., Harvey, P., Berg, P., Ulrich, R., Pedersen, A., Schmidt, R., Butler, A., Fransen, A. W. C., Klinge, D., Thomsen, M., Falthammar, C.-G., Lindqvist, P.-A., Christenson, S., Holtet, J., Lybekk, B., Sten, T. A., Tanskanen, P., Lappalainen, K., and Wygant, J.: The Electric Field and Wave Experiment for the Cluster Mission, Space Sc. Rev., 79, 137-156, 1997.

Huang, S. Y., Zhou, M., Sahraoui, F., Deng, X. H., Pang, Y., Yuan, Z. G., Wei, Q., Wang, J. F., and Zhou, X. M.: Wave properties in the magnetic reconnection diffusion region with high $\beta$ : Application of the k-filtering method to Cluster multispacecraft data, J. Geophys. Res., 115, A12211, doi:10.1029/2010JA015335, 2010.

Johnstone, A. D., Alsop, C., Gurge, S., Carter, P. J., Coates, A. J., Coker, A. J., Fazakerley, A. N., Grande, M., Gowen, R. A., Gurgiolo, C., Hancock, B. K., Narheim, B., Preece, A., Sheather, P. H., Winningham, J. D., and Woodcliffe, R. D.: PEACE, a plasma electron and current experiment, Space Sci. Rev., 79, 351-398, doi:10.1023/A:1004938001388, 1997.

Le Contel, O., Roux, A., Jacquey, C., Robert, P., Berthomier, M., Chust, T., Grison, B., Angelopoulos, V., Sibeck, D., Chaston, C. C., Cully, C. M., Ergun, B., Glassmeier, K.-H., Auster, U., McFadden, J., Carlson, C., Larson, D., Bonnell, J. W., Mende, 
S., Russell, C. T., Donovan, E., Mann, I., and Singer, H.: Quasi-parallel whistler mode waves observed by THEMIS during near-earth dipolarizations, Ann. Geophys., 27, 2259-2275, doi:10.5194/angeo-27-2259-2009, 2009.

Li, X., Baker, D. N., Temerin, M., Reeves, G. D., and Belian, R. D.: Simulation of dispersionless injections and drift echoes of energetic electrons associated with substorms, Geophys. Res. Lett., 25, 3763-3766, doi:10.1029/1998GL900001, 1998.

Lui, A. T. Y.: Current disruption in the Earth's magnetosphere: Observations and models, J. Geophys. Res., 101, 13067-13088, doi:10.1029/96JA00079, 1996.

Lui, A. T. Y., Yoon, P. H., Mok, C., and Ryu, C.-M.: Inverse cascade feature in current disruption, J. Geophys. Res., 113, A00C06, doi:10.1029/2008JA013521, 2008.

Nakamura, R., Baumjohann, W., Klecker, B., Bogdanova, Y., Balogh, A., Rème, H., Bosqued, J. M., Dandouras, I., Sauvaud, J.-A., Glassmeier, K.-H., Kistler, L., Mouikis, C., Zhang, T. L., Eichelberger, H., and Runov, A.: Motion of the dipolarization front during a flow burst event observed by Cluster, Geophys. Res. Lett., 29, 1942, doi:10.1029/2002GL015763, 2002.

Nakamura, R., Baumjohann, W., Zhang, T. L., Carr, C. M., Balogh, A., Fornacon, K.-H., Georgescu, E., Rème, H., Dandouras, I., Takada, T., Volwerk, M., Asano, Y., Runov, A., Eichelberger, H., Klecker, B., Mouikis, C., Kistler, L. M., and Amm, O.: Cluster and Double Star observations of dipolarization, Ann. Geophys., 23, 2915-2920, doi:10.5194/angeo-23-2915-2005, 2005.

Nosé, M., Koshiishi, H., Matsumoto, H., C:son Brandt, P., Keika, K., Koga, K., Goka, T., and Obara, T.: Magnetic field dipolarization in the deep inner magnetosphere and its role in development of $\mathrm{O}^{+}$-rich ring current, J. Geophys. Res., 115, A00J03, doi:10.1029/2010JA015321, 2010.

Ohtani, S., Takahashi, K., Zanetti, L. J., Potemra, T. A., McEntire, R. W., and Iijima, T.: Initial signatures of magnetic field and energetic particle fluxes at tail reconfiguration: Explosive growth phase, J. Geophys. Res., 97, 19311-19324, doi:10.1029/92JA01832, 1992.

Ohtani, S., Shay, M. A., and Mukai, T.: Temporal structure of the fast convective flow in the plasma sheet: Comparison between observations and two-fluid simulations, J. Geophys. Res., 109, A03210, doi:10.1029/2003JA010002, 2004.

Ono, Y., Nosé, M., Christon, S. P., and Lui, A. T. Y.: The role of magnetic field fluctuations in nonadiabatic acceleration of ions during dipolarization, J. Geophys. Res., 114, A05209, doi:10.1029/2008JA013918, 2009.

Pinçon, J. L. and Lefeuvre, F.: Local characterization of homogeneous turbulence in a space plasma from simultaneous measurements of field components at several points in space, J. Geophys. Res., 96, 1789-1802, 1991.

Pinçon, J. L. and Motschmann, U.: Multi-spacecraft filtering: General framework, in: Analysis Methods for Multi-Spacecraft Data, edited by: Paschmann, G. and Daly, P. W., pp. 65-78, Int. Space Sci. Inst., Bern, Switzerland, 1998.

Rème, H., Aoustin, C., Bosqued, J. M., Dandouras, I., Lavraud, B., Sauvaud, J. A., Barthe, A., Bouyssou, J., Camus, Th., CoeurJoly, O., Cros, A., Cuvilo, J., Ducay, F., Garbarowitz, Y., Medale, J. L., Penou, E., Perrier, H., Romefort, D., Rouzaud, J., Vallat, C., Alcaydé, D., Jacquey, C., Mazelle, C., d’Uston, C., Möbius, E., Kistler, L. M., Crocker, K., Granoff, M., Mouikis, C., Popecki, M., Vosbury, M., Klecker, B., Hovestadt, D., Kucharek, H.,
Kuenneth, E., Paschmann, G., Scholer, M., Sckopke, N., Seidenschwang, E., Carlson, C. W., Curtis, D. W., Ingraham, C., Lin, R. P., McFadden, J. P., Parks, G. K., Phan, T., Formisano, V., Amata, E., Bavassano-Cattaneo, M. B., Baldetti, P., Bruno, R., Chionchio, G., Di Lellis, A., Marcucci, M. F., Pallocchia, G., Korth, A., Daly, P. W., Graeve, B., Rosenbauer, H., Vasyliunas, V., McCarthy, M., Wilber, M., Eliasson, L., Lundin, R., Olsen, S., Shelley, E. G., Fuselier, S., Ghielmetti, A. G., Lennartsson, W., Escoubet, C. P., Balsiger, H., Friedel, R., Cao, J.-B., Kovrazhkin, R. A., Papamastorakis, I., Pellat, R., Scudder, J., and Sonnerup, B.: First multispacecraft ion measurements in and near the Earth's magnetosphere with the identical Cluster ion spectrometry (CIS) experiment, Ann. Geophys., 19, 1303-1354, doi:10.5194/angeo19-1303-2001, 2001.

Ronnmark, K.: WHAMP-Waves in homogeneous anisotropic multi component plasmas, Kiruna Geophysical Institute Report, 179, 1982.

Runov, A., Angelopoulos, V., Sitnov, M. I., Sergeev, V. A., Bonnell, J., McFadden, J. P., Larson, D., Glassmeier, K.H., and Auster, U.: THEMIS observations of an earthwardpropagating dipolarization front, Geophys. Res. Lett., 36, L14106, doi:10.1029/2009GL038980, 2009.

Sahraoui, F., Pinçon, J. L., Belmont, G., Rezeau, L., CornilleauWehrlin, N., Robert, P., Mellul, L., Bosqued, J. M., Canu, P., Balogh, A., and Chanteur, G.: ULF wave identification in the magnetosheath: k-filtering technique applied to Cluster II data, J. Geophys. Res., 108, 1335, doi:10.1029/2002JA009587, 2003.

Sahraoui, F., Belmont, G., Rezeau, L., Cornilleau-Wehrlin, N., Pinçon, J. L., and Balogh, A.: Anisotropic turbulent spectra in the terrestrial magnetosheath as seen by the Cluster spacecraft, Phys. Rev. Lett., 96, 075002, doi:10.1103/PhysRevLett.96.075002, 2006.

Sahraoui, F., Belmont, G., Goldstein, M. L., and Rezeau, L.: Limitations of multispacecraft data techniques in measuring wave number spectra of space plasma turbulence, J. Geophys. Res., 115, A04206, doi:10.1029/2009JA014724, 2010a.

Sahraoui, F., Belmont, G., Goldstein, M. L., and Rezeau, L.: Three Dimensional Anisotropic k Spectra of Turbulence at Subproton Scales in the Solar Wind, Phys. Rev. Lett., 105, 131101, doi:10.1103/PhysRevLett.105.131101, 2010b.

Santolík, O., Parrot, M., and Lefeuvre, F.: Singular value decomposition methods for wave propagation analysis, Radio. Sci., 38, 1010, doi:10.1029/2000RS002523, 2003.

Sergeev, V. A., Angelopulous, V., Gosling, J. T., Cattell, C. A., and Russell, C. T.: Detection of localized, plasma-depleted flux tubes or bubbles in the midtail plasma sheet, J. Geophys. Res., 101, 10817-10826, 1996.

Sergeev, V., Angelopoulos, V., Apatenkov, S., Bonnell, J., Ergun, R., Nakamura, R., McFadden, J., Larson, D., and Runov, A.: Kinetic structure of the sharp injection/dipolarization front in the flow-braking region, Geophys. Res. Lett., 36, L21105, doi:10.1029/2009GL040658, 2009.

Shiokawa, K., Baumjohann, W., and Haerende, G.: Braking of high-speed flows in the near-Earth tail, Geophys. Res. Lett., 24, 1179-1182, 1997.

Shiokawa, K., Miyashita, Y., Shinohara, I., and Matsuoka, A.: Decrease in $\mathrm{Bz}$ prior to the dipolarization in the near-Earth plasma sheet, J. Geophys. Res., 110, A09219, doi:10.1029/2005JA011144, 2005. 
Sitnov, M. I., Swisdak, M., and Divin, A. V.: Dipolarization fronts as a signature of transient reconnection in the magnetotail, J. Geophys. Res., 114, A04202, doi:10.1029/2008JA013980, 2009. Wilken, B., Daly, P. W., Mall, U., Aarsnes, K., Baker, D. N., Belian, R. D., Blake, J. B., Borg, H., Büchner, J., Carter, M., Fennell, J. F., Friedel, R., Fritz, T. A., Gliem, F., Grande, M., Kecskemety, K., Kettmann, G., Korth, A., Livi, S., McKenna-Lawlor, S., Mursula, K., Nikutowski, B., Perry, C. H., Pu, Z. Y., Roeder, J., Reeves, G. D., Sarris, E. T., Sandahl, I., Søraas, F., Woch, J., and Zong, Q.-G.: First results from the RAPID imaging energetic particle spectrometer on board Cluster, Ann. Geophys., 19, 1355-1366, doi:10.5194/angeo-19-1355-2001, 2001.

Wu, P., Fritz, T. A., Larvaud, B., and Lucek, E.: Substorm associated magnetotail energetic electrons pitch angle evolutions and flow reversals: Cluster observation, Geophys. Res. Lett., 33, L17101, doi:10.1029/2006GL026595, 2006.
Yoon, P. H., Lui, A. T. Y., and Bonnell, J. W.: Identification of plasma instability from wavelet spectra in a current disruption event, J. Geophys. Res., 114, A04207, doi:10.1029/2008JA013816, 2009.

Zhou, M., Ashour-Abdalla, M., Deng, X., Schriver, D., ElAlaoui, M., and Pang, Y.: THEMIS observation of multiple dipolarization fronts and associated wave characteristics in the near-Earth magnetotail, Geophys. Res. Lett., 36, L20107, doi:10.1029/2009GL040663, 2009.

Zhou, M., Huang, S., Deng, X., and Pang, Y.: Observation of a Sharp Negative Dipolarization Front in the Reconnection Outflow Region, Chinese Phys. Lett., 28, 109402, doi:10.1088/0256307X/28/10/109402, 2011. 